\title{
Open Porosity and Pore Size Distribution of Mesoporous Silica Films Investigated by Positron Annihilation Lifetime Spectroscopy and Ellipsometric Porosimetry
}

\author{
Bangyun Xiong ${ }^{1, *}$, Jingjing $\mathrm{Li}^{1}$, Chunqing $\mathrm{He}^{2, *}$, Jiale Lai $^{1}$, Xiangjia Liu ${ }^{1}$ and Tao Huang ${ }^{1}$ \\ 1 Guangdong Key Laboratory for Hydrogen Energy Technologies, School of Materials Science and Hydrogen \\ Energy, Foshan University, Foshan 528000, China; lijingjing0842@163.com (J.L.); sg1010594845@163.com (J.L.); \\ liuxiangjia6@163.com (X.L.); huangtao9902@163.com (T.H.) \\ 2 Key Laboratory of Nuclear Solid State Physics Hubei Province, School of Physics and Technology, \\ Wuhan University, Wuhan 430072, China \\ * Correspondence: xiongbangyun@fosu.edu.cn (B.X.); hecq@whu.edu.cn (C.H.)
}

Citation: Xiong, B.; Li, J.; He, C.; Lai, J.; Liu, X.; Huang, T. Open Porosity and Pore Size Distribution of Mesoporous Silica Films Investigated by Positron Annihilation Lifetime Spectroscopy and Ellipsometric Porosimetry. Materials 2021, 14, 3371. https://doi.org/10.3390/ma14123371

Academic Editor: Filip Tuomisto

Received: 17 May 2021

Accepted: 16 June 2021

Published: 18 June 2021

Publisher's Note: MDPI stays neutral with regard to jurisdictional claims in published maps and institutional affiliations.

Copyright: () 2021 by the authors. Licensee MDPI, Basel, Switzerland. This article is an open access article distributed under the terms and conditions of the Creative Commons Attribution (CC BY) license (https:// creativecommons.org/licenses/by/ $4.0 /)$.

\begin{abstract}
Tunable mesoporous silica films were prepared though a sol-gel process directed by the self-assembly of various triblock copolymers. Positron annihilation $\gamma$-ray energy spectroscopy and positron annihilation lifetime spectroscopy (PALS) based on intense pulsed slow positron beams as well as ellipsometric porosimetry (EP) combined with heptane adsorption were utilized to characterize the open porosity/interconnectivity and pore size distribution for the prepared films. The consistency between the open porosities was examined by the variations of orthopositronium (o-Ps) $3 \gamma$ annihilation fractions and the total adsorbed volumes of heptane. The average pore sizes deduced by PALS from the longest-lived o-Ps lifetimes are in good agreement with those by EP on the basis of the Barrett-Joyner-Halenda model, as indicated by a well fitted line of slope $k=1$. The results indicate that the EP combined with heptane adsorption is a useful method with high sensitivity for calibrating the mesopore size in highly interconnected mesoporous films, whereas PALS is a novel, complementary tool for characterizing both closed and open pores in them.
\end{abstract}

Keywords: open porosity; mesopore size; orthopositronium lifetime; positron annihilation lifetime spectroscopy; ellipsometric porosimetry

\section{Introduction}

Mesoporous silica films have been extensively developed as separations, low-dielectric interlayers, catalysts, gas sensors and adsorbents. Accurate control of the pore structure of mesoporous silica is one of the most important issues for realizing its practical application or expanding its specific application scope. The introduction of nanoscaled pores into silica films has aroused great interest by using nonionic triblock copolymers [1-4] as structural templates to tailor the pore size and morphology, benefitting from the self-organizing ability of amphiphilic copolymers [4]. Meanwhile, accurate characterization of pore structures is of great significance to improve the performance of functional silica films with specific pore characteristics.

However, it is difficult for most traditional techniques to characterize nanopores in submicron thin films fabricated on thick solid substrates. For instance, transmission electron microscopy (TEM) is a common resort to probe the pore morphology of films [5]. However, the films must be scraped or sliced from the substrates, resulting in fragmentation, which may not reflect the porosity of the intact films. Positron annihilation $\gamma$-ray energy spectroscopy (PAES) [6,7] and positron annihilation lifetime spectroscopy (PALS) [8-10] based on an intense pulsed positron beam have been proven as powerful and sensitive tools to elucidate the nanoporosity of thin films on substrates. Ellipsometric porosimetry (EP) combined with vapor adsorption has been successfully used to evaluate the open 
porosity of thin films $[5,11]$. Therefore, the combined application of PAES, PALS and EP is expected to provide more detailed and reliable characterization for the difference in the mesostructures of silica films.

In the present work, controllable mesoporous silica films were fabricated with the assistance of different BASF triblock copolymers via a sol-gel route. The pore structures of the fabricated films, such as pore interconnectivity /open porosity and pore size, were examined by means of PAES, PALS and EP. The feasibility of PALS based on a slow positron beam for accurately characterizing both closed and open pores in thin silica films was verified by comparative studies on their mesoporosities measured by both PALS and EP combined with vapor adsorption.

\section{Materials and Methods}

\subsection{Preparation of Mesoporous Silica Films}

A sol-gel process in accordance with the reported procedure [12] was applied to synthesize mesoporous silica films with adjustable mesopore sizes and morphologies. Tetraethoxysilane (TEOS) was selected as the silica skeleton precursor. Amphiphilic BASF Pluronic surfactants such as triblock copolymers F127 (EO $\left.\mathrm{EO}_{106} \mathrm{PO}_{70} \mathrm{EO}_{106}, \mathrm{M}_{\mathrm{w}}=12,600 \mathrm{~g} / \mathrm{mol}\right)$, F88 $\left(\mathrm{EO}_{100} \mathrm{PO}_{39} \mathrm{EO}_{100}, \mathrm{M}_{\mathrm{W}}=11,400 \mathrm{~g} / \mathrm{mol}\right), \mathrm{F} 38\left(\mathrm{EO}_{43} \mathrm{PO}_{14} \mathrm{EO}_{43}, \mathrm{M}_{\mathrm{w}}=4700 \mathrm{~g} / \mathrm{mol}\right)$ and P103 $\left(\mathrm{EO}_{17} \mathrm{PO}_{85} \mathrm{EO}_{17}, \mathrm{M}_{\mathrm{W}}=4950 \mathrm{~g} / \mathrm{mol}\right)$ were introduced as the templating agents, respectively. A surfactant solution was prepared by dissolving a fixed amount of $3.02 \mathrm{~g}$ BASF surfactant (denoted by $\mathrm{EO}_{x} \mathrm{PO}_{y} \mathrm{EO}_{x}$, where $x$ and $y$ are determined by the above triblock copolymers) in $40 \mathrm{~mL}$ anhydrous alcohol (EtOH). Typically, a precursor solution containing TEOS, $\mathrm{EtOH}$, $\mathrm{HCl}$ and $\mathrm{H}_{2} \mathrm{O}$ was developed under stirring at $100{ }^{\circ} \mathrm{C}$. The precursor solution was aged at $100{ }^{\circ} \mathrm{C}$ for $30 \mathrm{~min}$ followed by the addition of the above surfactant solution. The mixed solution was continuously stirred for $1 \mathrm{~h}$. The masses of the respective compositions in the final sols were $3.02 \mathrm{~g} \mathrm{EO}_{x} \mathrm{PO}_{y} \mathrm{EO}_{x}, 8.33 \mathrm{~g}$ TEOS, $55.28 \mathrm{~g} \mathrm{EtOH}, 5.76 \mathrm{~g} \mathrm{H}_{2} \mathrm{O}$, and $0.0042 \mathrm{~g}$ $\mathrm{HCl}$. The mass ratio of $\mathrm{EO}_{x} \mathrm{PO}_{y} \mathrm{EO}_{x}$ to TEOS was around $36.25 \%$. The weight ratio of $\mathrm{EO}_{x} \mathrm{PO}_{y} \mathrm{EO}_{x}$ in all final sols was calculated to be about $4.2 \mathrm{wt} \%$.

The final precursor sol was subsequently deposited on a polished monocrystalline silicon (100) wafer by dip-coating $[13,14]$ with a speed of $30 \mathrm{~cm} / \mathrm{min}$. The as-deposited film was then cured at $100{ }^{\circ} \mathrm{C}$ for $3 \mathrm{~h}$ and finally calcined at $450{ }^{\circ} \mathrm{C}$ for $3 \mathrm{~h}$ to decompose the surfactant template. For convenience, the mesoporous silica thin films were represented by their corresponding surfactant names. Further, an additional set of the same films were capped by nonporous $\mathrm{SiO}_{2}$ layers (about $20 \mathrm{~nm}$ in thickness) through electron-beam sputtering [15] for PALS experiments.

\subsection{PAES and PALS Based on Intense Pulsed Slow Positron Beams}

All pore characterization experiments were done at the National Institute of Advanced Industrial Science and Technology, Tsukuba, Japan. Positron annihilation $\gamma$-ray energy spectra were conducted by a variable-energy pulsed slow positron beam with a Ge detector $[5,7]$, both for the uncapped silica films and capped ones. The orthopositronium (o-Ps) $3 \gamma$ annihilation fraction $\left(I_{3 \gamma}\right)$ was estimated from the recorded $\gamma$-ray energy spectrum as described elsewhere [16-19]. Positron annihilation lifetime spectra of the capped silica films were collected using an intense pulsed positron beam $[11,12,15,20]$. The incident positron energy $\left(E_{\mathrm{in}}\right)$ was fixed at $2 \mathrm{keV}$, at which the vast majority of positrons were injected into the inside thin films. The total annihilation event counts for each spectrum was approximately 5 million. The time resolution was around $330 \mathrm{ps}$. Background subtraction was performed by using the positron annihilation lifetime spectrum of Kapton film for reference [3]. All films were heated at $250{ }^{\circ} \mathrm{C}$ for $30 \mathrm{~min}$ in nitrogen $\left(\mathrm{N}_{2}\right)$ atmosphere to eliminate some adsorbed water before the positron annihilation measurements. A continuous o-Ps lifetime distribution was deduced from the measured positron annihilation lifetime spectra by CONTIN program [21]. On the basis of the rectangular Tao-Eldrup (RTE) model [10,22,23], the mesopore side length $\left(a_{\text {PALS }}\right)$ was computed from the longest-lived lifetime of o-Ps. 


\subsection{Ellipsometric Porosimetry Combined with Heptane Adsorption}

The schematic diagram of the apparatus of heptane adsorption is available in the supplementary materials. A silica thin film was installed in the sample chamber equipped with an ellipsometric porosimeter, an ultrahigh vacuum pump, a temperature control console and a system for dosing heptane. The sample chamber was degassed to $10^{-5}$ torr, and the film was heated at $250{ }^{\circ} \mathrm{C}$ for $30 \mathrm{~min}$. When the temperature dropped to $30^{\circ} \mathrm{C}$, heptane was introduced into the chamber up to a certain pressure $(p)$, which is in the range of $0.02 \sim 46.88$ torr. The partial pressure $\left(p / p_{0}\right)$ is defined as the ratio of the heptane pressure $(p)$ to the saturated vapor pressure of heptane $\left(p_{0}\right)$, ranging from 0.003 to 0.803 determined by the dosing heptane. For each $p / p_{0}$, the ellipsometric spectrum was measured at $30{ }^{\circ} \mathrm{C}$ for the film filled by heptane. The characteristic parameters $\Psi$ and $\Delta$ were fitted over wavelengths from 300 to $800 \mathrm{~nm}$ assuming the Cauchy model [24]. The observed refractive index $\left(n_{\mathrm{o}}\right)$ at $630 \mathrm{~nm}$ was computed from the fitted ellipsometric parameters upon successive heptane adsorption-desorption versus $p / p_{0}$. The pore volume fractions filled with heptane $\left(V_{\text {filled }}\right)$ were estimated in accordance with the following deduced Lorentz-Lorenz formula [25]:

$$
V_{\text {filled }}=\left(\frac{n_{\mathrm{o}}^{2}-1}{n_{\mathrm{o}}^{2}+2}-\frac{n_{f}^{2}-1}{n_{f}^{2}+2}\right) /\left(\frac{n_{a}^{2}-1}{n_{a}^{2}+2}\right)
$$

In this study, $n_{f}$ refers to the fixed refractive index of the silica film at $p / p_{0}=0$ and $n_{a}$ represents the refractive index of adsorbate $\left(n_{\text {heptane }}=1.386\right)[25,26]$. Hence, the physical adsorption isotherms of heptane were measured by the changes of $V_{\text {filled }}$ values with $p / p_{0}$ according to Equation (1) with the measured $n_{\mathrm{o}}$. The open porosities of the films were associated with the total adsorbed volumes of heptane at the high $p / p_{0}$ regions.

Starting from the vacuum, as the $p / p_{0}$ increases, the micropores (pore radius below $1 \mathrm{~nm}$ ) at first are filled by the heptane. The pore surfaces are occupied layer-by-layer by adsorption. The thickness of the adsorbed layer $(t)$ increases progressively with $p / p_{0}$, which can be expressed as [25]

$$
t=5 t_{m} \lg \frac{p}{p_{0}}
$$

where $t_{m}$ denotes the thickness of monolayer adsorption of heptane, and $0.38 \mathrm{~nm}$ was applied to the value of $t_{m}$ in Equation (2) [27]. For higher $p / p_{0}$, the capillary condensation takes place. The Kelvin radius $\left(r_{K}\right)$ is determined by the following Kelvin equation [28,29]:

$$
r_{K}=\frac{2 \gamma V_{L}}{R T} \ln \frac{p}{p_{0}}
$$

where $\gamma$ and $V_{L}$ refer to the surface tension and molar volume of heptane, respectively. $R$ stands for the ideal gas constant. $T$ is the temperature, $T=303 \mathrm{~K}$ for the present work. Capillary condensation happens in mesopores. Under the assumption of the cylindrical pores, the pore radius $(R)$ was therefore estimated by the $r_{K}$ and $t$,

$$
R=r_{K}+t
$$

From the physisorption isotherms, the $V_{\text {filled }}$ is a function of $p / p_{0}$, namely $V_{\text {filled }}=f$ $\left(p / p_{0}\right)$. Thus, $R=f\left(p / p_{0}\right)$ is evaluated. The pore size distribution (PSD) is calculated as the change of $\mathrm{d} V / \mathrm{d} R$ with $R$ from the desorption data. To the first order approximation, under assumption of a symmetrical and unimodal PSD, the average pore radius correlates with the maximum value of the PSD [29].

\section{Results and Discussion}

\subsection{Pore Interconnectivity/Open Porosity of the Mesoporous Silica Films}

Figure 1 shows $I_{3 \gamma}$ as functions of $E_{\text {in }}$ both for the uncapped films (open symbols) and capped ones (solid symbols), where the data for the F38 and F127 templated films 
were described in a previous paper [5]. As shown in a typical $I_{3 \gamma}-E_{\text {in }}$ profile, such as for the uncapped F38 templated film, $I_{3 \gamma}$ climbs gradually as $E_{\text {in }}$ increases to $\sim 1.0 \mathrm{keV}$, due to o-Ps escaping from adjacent film surface and annihilation in vacuum. $I_{3 \gamma}$ almost remains unchanged with the increase of $E_{\text {in }}$ up to $\sim 2.5 \mathrm{keV}$, which is attributable to positronium (Ps) formation and Ps emission from the inside mesoporous film [7]. More and more positrons are injected into the silicon substrate with the further increase of $E_{\text {in }}$. It is well known that there is no Ps formation in silicon so that $I_{3 \gamma}$ drops gradually to zero.

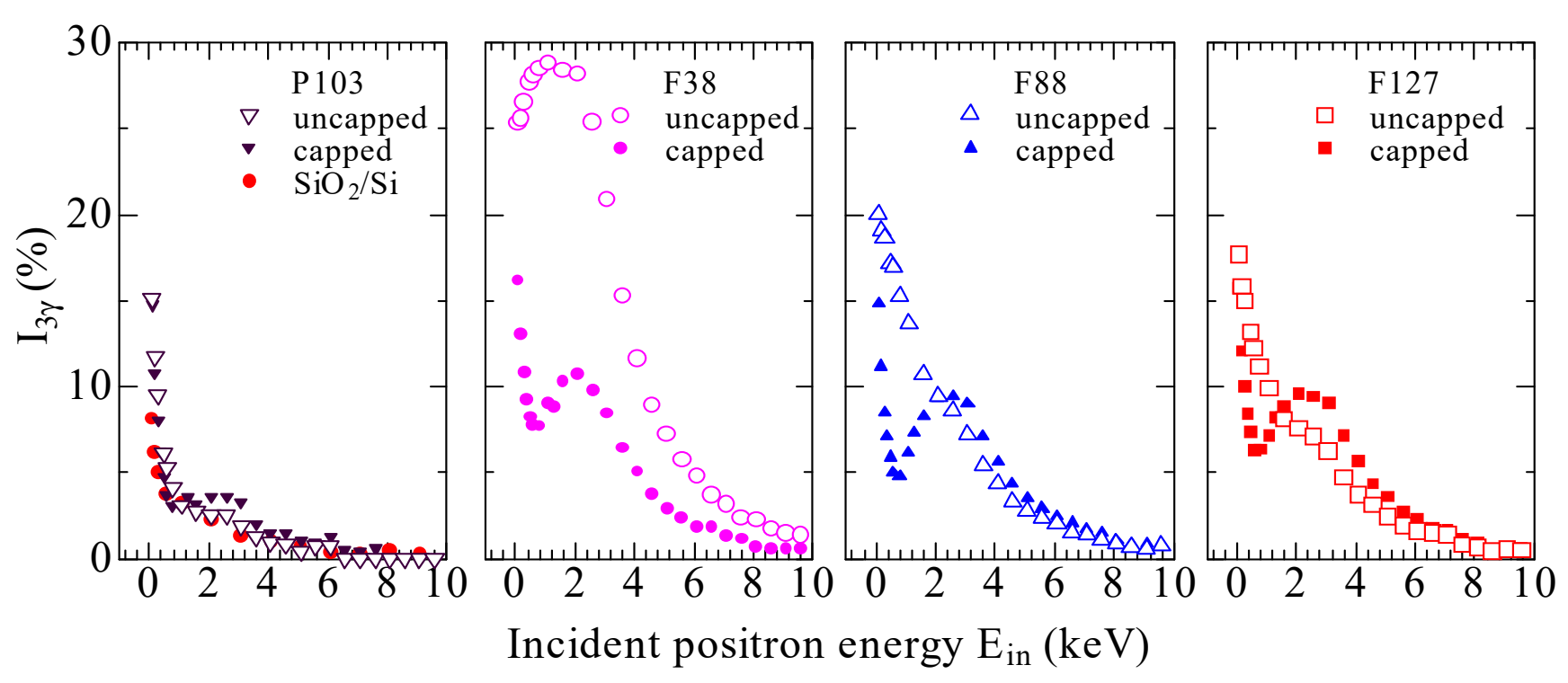

Figure 1. The $I_{3 \gamma}-E_{\text {in }}$ curves both for the uncapped films prepared with various triblock copolymers (open symbols) and the corresponding capped ones (solid symbols). (The $I_{3 \gamma}-E_{\text {in }}$ profiles for the films prepared with F38 and F127 are reprinted with permission from [5]. Copyright 2012 American Physical Society).

The uncapped films prepared with different templates show their own characteristics in $I_{3 \gamma}$ profiles $\left(E_{\mathrm{in}}<3.0 \mathrm{keV}\right)$. For the film with $\mathrm{F} 38$, the initial increase and gradual decrease of $I_{3 \gamma}$ suggests a high pore interconnectivity [7]. The initial increase and plateau of $I_{3 \gamma}$ disappear for the other three films. For the film prepared with P103, $I_{3 \gamma}$ falls sharply to a quite low value $(\sim 3 \%)$ with increasing $E_{\text {in }}$ to $\sim 1.0 \mathrm{keV}$, indicative of few Ps atoms capable of emitting out from the inside film with low pore interconnectivity [6]. High Ps diffusion coefficients through well-connected pores [7] are revealed by the gradual decline of $I_{3 \gamma}$ with the increase of $E_{\text {in }}$ to $\sim 3.0 \mathrm{keV}$ for the films templated by F88 and F127. It is worth noting that for the two films, the open porosity /interconnectivity are very high, despite their lower $I_{3 \gamma}$ values in comparison with that for the film with F38. As was observed by the TEM images reported previously [5], worm-like pores and cage-like pores are formed in the film with F38 and F127, respectively. The larger cages are interconnected via smaller channels, which make thermalized Ps atoms likely confined in the larger cages and hardly able to pass through the smaller tubular channels between the cages to diffuse out from the films due to the Ps quantum confinement effect $[5,30,31]$. The results suggest that Ps diffusion is strongly affected both by open porosity/interconnectivity and pore morphology [32].

For the film prepared with P103, the $I_{3 \gamma}-E_{\text {in }}$ curves are almost identical with and without capping a nonporous $\mathrm{SiO}_{2}$ layer on the film surface, which are likewise well coincided with the $I_{3 \gamma}-E_{\text {in }}$ curve for the $\mathrm{SiO}_{2} / \mathrm{Si}$ film prepared without copolymer. The result directly evidences that most pores are closed in the film with P103. It is rational to observe the similar tendency of $I_{3 \gamma}-E_{\text {in }}$ curves for the capped films with F38, F88 and F127 because the nonporous $\mathrm{SiO}_{2}$ capping layers inhibit o-Ps escaping from the films [5], except that the peak/plateau moves to higher $E_{\text {in }}$ due to the increase of the film thickness. 
Therefore, the variations of $I_{3 \gamma}$ show that closed pores are fabricated in P103 templated film, but pores are well interconnected to the film surfaces in the other three ones.

Figure 2 depicts the heptane adsorption-desorption isotherms at $303 \mathrm{~K}$ for the mesoporous films fabricated with different surfactants as functions of $p / p_{0}$, where the ones templated by F38 and F127 were displayed previously [5]. The heptane physisorption isotherms of the silica films are found to be varied by the selection of different surfactants. For the three films except the film prepared with P103, the adsorption-desorption processes show a type IV isotherm, signifying mesostructures [33-35]. For the film templated by F38, a type pseudo-H1 hysteresis loop [36] is observed, likely indicative of disordered tube-like pores, confirmed with the worm-like pores by TEM [5]. The H1 loop exists in materials with narrow ranges of uniform mesopores [37]. However, type $\mathrm{H} 5$ hysteresis loops [37] are seen for the F88 and F127 templated films. The H5 loop exhibits a unique form related to special pore structures including both open and partly closed mesopores [37], consistent with the cage-like pores interconnected by the smaller tubular channels [5]. Moreover, the capillary condensation step at $p / p_{0}$ moves from around 0.2 for the film template by F88 to about 0.3 for the one by F127, owing to the formation of larger mesopores in the latter.

\section{Heptane adsorption isotherms at $303 \mathrm{~K}$}

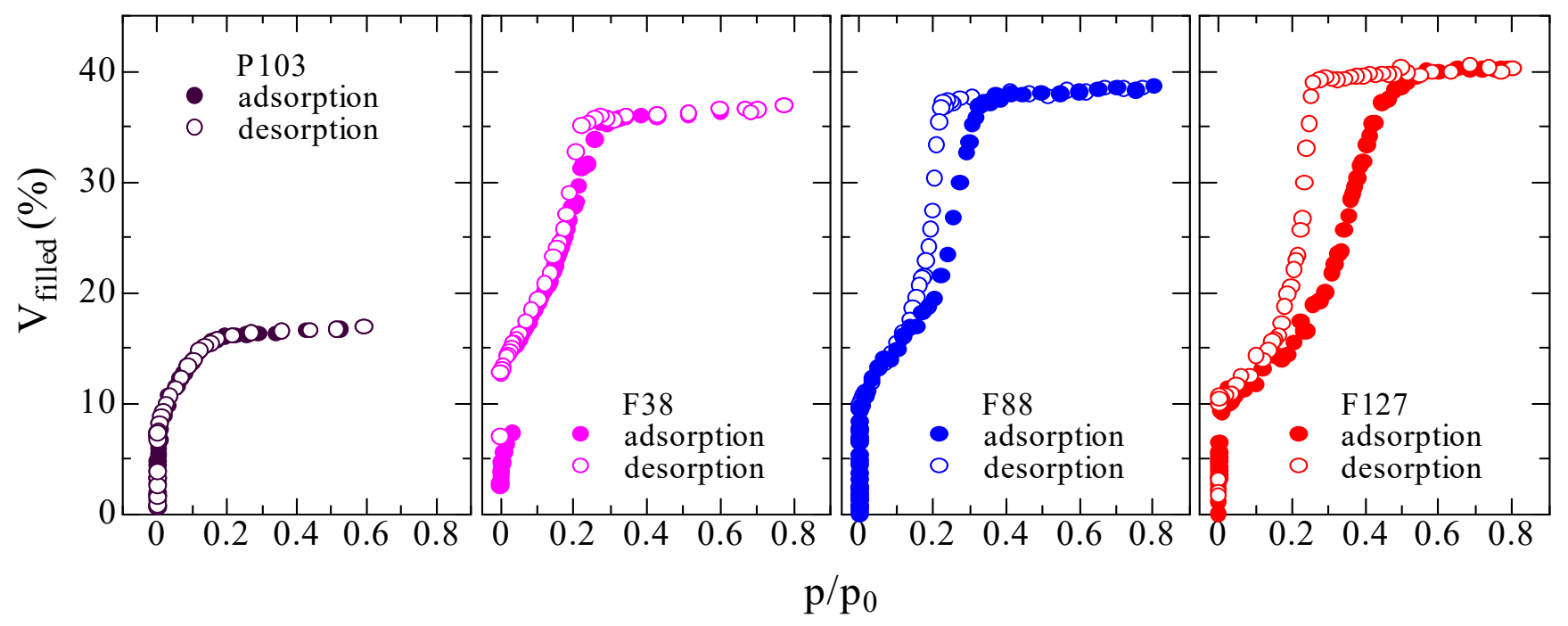

Figure 2. The heptane adsorption-desorption isotherms at $30{ }^{\circ} \mathrm{C}(303 \mathrm{~K})$ of the mesoporous silica films prepared with P103, F38, F88 and F127, respectively. (The isotherms for the films with F38 and F127 are reprinted with permission from [5]. Copyright 2012 American Physical Society).

Interestingly, for the film prepared with P103, $V_{\text {filled }}$ increases sharply with increasing $p / p_{0}$ from zero to about 0.2 , and it keeps at a constant value with increasing $p / p_{0}$ from $\sim 0.2$ to 0.6 , corresponding to a reversible type I isotherm, a well-known Langmuir monolayer adsorption isotherm [38]. Type I isotherms exist in materials with a wider PSD, containing wider micropores and possibly narrower mesopores (of width $<\sim 2.5 \mathrm{~nm}$ ) [37]. The heptane gas is no longer adsorbed even though $p / p_{0}$ is further increased to higher than 0.6 , showing no larger open pores in the P103 templated film, as indicated by its absent hysteresis loop. $V_{\text {filled }}$ reach constant values with increasing $p / p_{0}$ above $0.2,0.3,0.35$ and 0.5 for the film with P103, F38, F88 and F127, respectively, attributed to their open porosity/interconnectivity for corresponding silica films. The open porosities related to the total adsorbed volumes of heptane at the high $p / p_{0}$ regions [11] are calculated to be $16.9,37.0,38.6$ and $40.3 \%$, for the films with P103, F38, F88 and F127, respectively. Among the four films, the highest open porosity/interconnectivity is revealed by EP in the film template by F127, coincident with the above discussion on the variation of $I_{3 \gamma}$. 


\subsection{Pore Size Distribution of the Mesoporous Silica Films}

Positron annihilation lifetime spectra recorded at $E_{\text {in }}=2 \mathrm{keV}$ are demonstrated in Figure 3 for the capped films with different triblock copolymers, where those except for the F88 templated film were depicted previously [12]. Obviously, a longest-lived lifetime component resulted from o-Ps annihilation in mesopores can be seen for all films. The longest-lived components of the capped silica films change evidently, demonstrating adjustable pore sizes by the selection of templating agent [12]. The slope of o-Ps component for the films templated by various surfactants is in the order of F127 $<\mathrm{F} 88<\mathrm{F} 38<\mathrm{P} 103$, which shows that the average pore size is in the order of F127 $>$ F88 $>$ F38 $>$ P103.

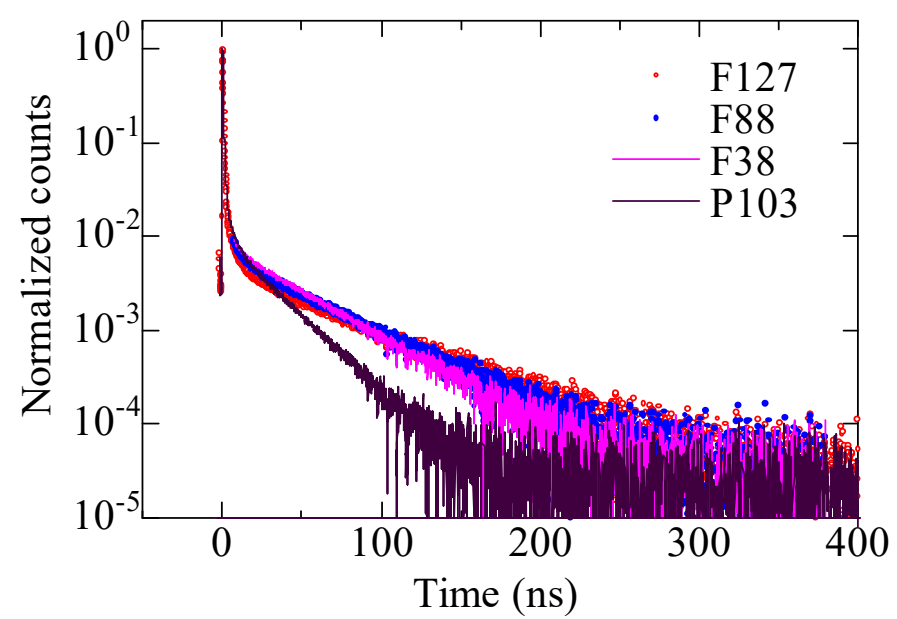

Figure 3. Positron annihilation lifetime spectra recorded at $E_{\text {in }}=2 \mathrm{keV}$ for the capped mesoporous silica films prepared with P103, F38, F88 and F127, respectively. (Positron annihilation lifetime spectra for the films with P103, F38 and F127 are reprinted with permission from [12]. Copyright 2006 Elsevier).

Pore size distributions (PSDs) of the films with various templates are displayed in Figure 4, calculated (a) by PALS according to the RTE model $[10,22,23]$ from the longestlived o-Ps lifetime distributions of Figure 3 and (b) by EP based on the BJH model [39] from the corresponding desorption isotherms of Figure 2. For the F38 templated film with worm-like channels, the pore size was calculated by PALS under assumption of rectangular pores because of its high interconnectivity, while the pore size of cage-like pores was calculated assuming cubic pores for the other three films. Predominant peaks of PSD can be seen for all films. The average pore sizes deduced by PALS are very close to those by EP. The average pore side lengths by PALS are about 2.60, 2.96, 4.37 and $5.63 \mathrm{~nm}$ for the films with P103, F38, F88 and F127, respectively, and the BJH pore diameters are around 2.20, $3.25,4.18$ and $5.46 \mathrm{~nm}$, respectively.

Nevertheless, as demonstrated in Figure $4 b$, the height of BJH PSD peak for the film with P103 is very low because of the inaccessibility for gas molecules into closed pores. However, positrons can be implanted inside the film and Ps atoms are preferentially localized in closed pores and annihilate therein, showing an obvious PSD peak of P103 templated film in Figure 4a. The full width at half maximum of PSD by PALS is much higher than that by EP for the film templated by F38, because positrons can be trapped by micro/mesopores that smaller than the minimum size pores detected by EP, resulting in a broader PSD. The result indicates that PALS has more advantages in characterizing closed pores and meso/micropore size distributions in mesoporous thin films. 

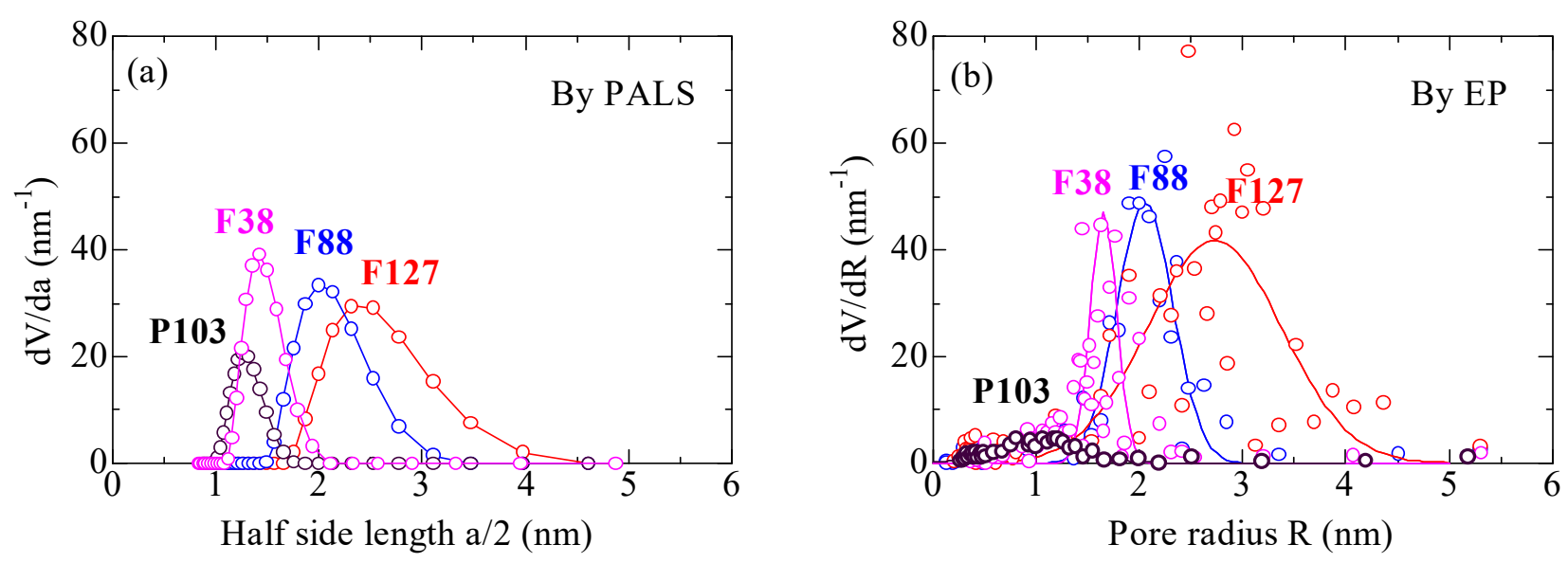

Figure 4. Pore size distributions of the films with various templates calculated by (a) PALS and (b) EP.

For the films templated by F88 and F127, both the PSD by PALS and the BJH PSD are much broader than those for the film with F38. As is revealed by the hysteresis loops as well as the TEM observations [5], uniform worm-like pores are formed in the film with F38, and more generous cage-like pores exist in the films with F88 and F127. The cage-like pores consist of larger cages and relatively smaller connecting channels. For instance, the mean pore size of the connecting channels between neighboring cages was determined around $2.5 \mathrm{~nm}$ for the film templated by F127 in the same way as previously published [2]. Heterogeneity of coexistence of cages and tubular channels probably results in broader PSDs in the films templated by F88 and F127.

\subsection{Comparison of Open Porosity and Pore Size by PALS and EP}

The comparison of the average pore sizes obtained by PALS ( $\left.a_{\text {PALS }}\right)$ and EP ( $\left.D_{\mathrm{EP}}\right)$ is plotted in Figure 5. The circle represents the pore size calculated by the two methods. All the pore sizes fall on a fitted line of slope $k=1$ with the fitting variation of $\mathrm{R}^{2}=0.96$, as seen red line in Figure 5. The linear fitting $\mathrm{R}^{2}$ approaches to 1 , indicating that both PALS and EP can precisely measure the mesopore size of porous silica films prepared with various polymeric templates. Further, the fitting result shows that relatively larger average pore sizes were obtained by PALS, because Ps atoms were preferentially localized in larger pores.

The open porosities measured by $\mathrm{EP}\left(P_{\mathrm{EP}}\right)$ (black solid circles) and pore sizes obtained by PALS (red solid triangles) and EP (blue open triangles), respectively, versus the refractive index as well as the copolymer templates are exhibited in Figure 6. The black dashed line is the linear fitting results of the refractive index dependence of the open porosity. The $P_{\mathrm{EP}}$ is evaluated by the simplified Lorentz-Lorenz equation, as formulated in Equation (1) with the measured $n_{\mathrm{o}}$. A linear relationship between the open porosity and the refractive index appears for the films with various triblock copolymers. Interestingly, this relation offers the refractive index $n=1.466$ for nonporous silica if the line is extrapolated to open porosity for $P_{\mathrm{EP}}=0$. 


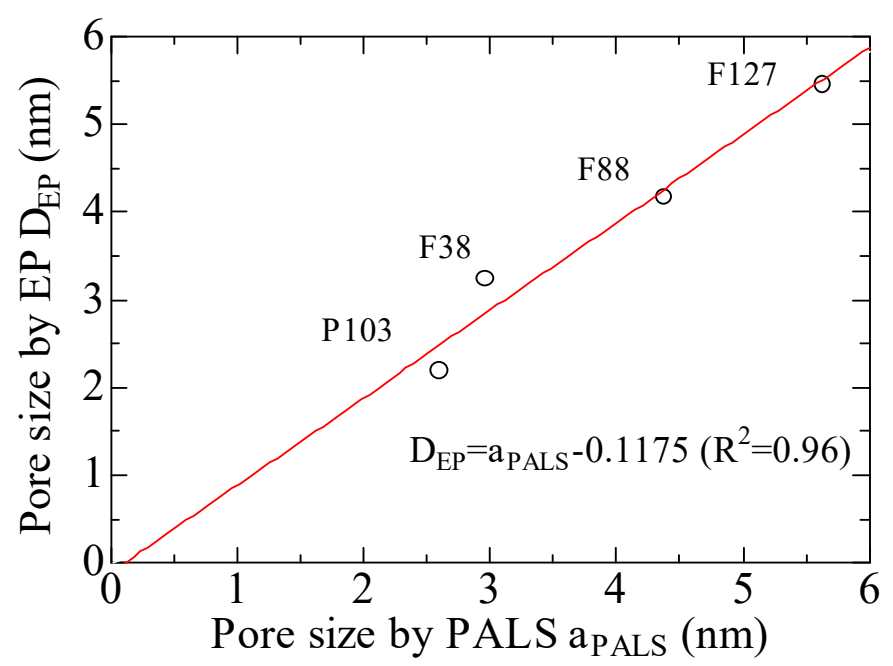

Figure 5. Pore sizes determined by EP of the films with various surfactants versus pore sizes by PALS.

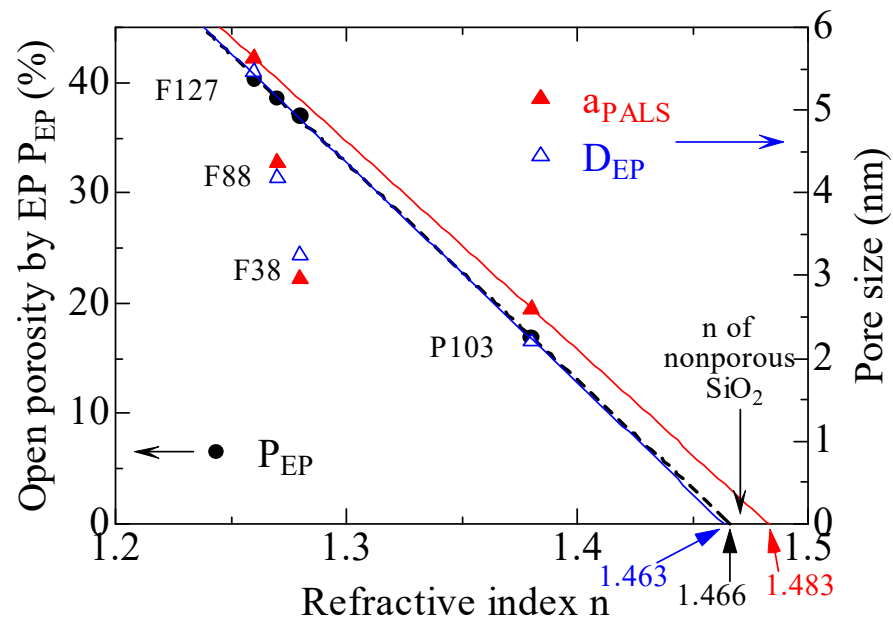

Figure 6. Open porosity measured by EP (black solid circles) and pore size by PALS (red solid triangles) and EP (blue open triangles), respectively, as a function of the refractive index as well as the copolymer templates.

The red and blue lines in Figure 6 represent the linear fitting results of the refractive index dependence of "closed" pore sizes by PALS and EP, respectively. Although the mesopores in the film synthesized by F127 are well interconnected and open to the film surface, the diffusion length of Ps atoms in it is relatively short, so from the point of view of Ps diffusion, the pores in both F127 and P103 templated films are so-called "closed". For the films with "closed" pores, it seems that the refractive index of nonporous $\mathrm{SiO}_{2}$ can be obtained for both PALS and EP, when the pore sizes are epitaxial to 0 . For the fitted bule line investigated by EP, the intercept on the horizontal axis, which represents the refractive index of nonporous $\mathrm{SiO}_{2}$, is 1.463, near to an ideal value of bulk fused quartz (1.460) [40]. Likewise, the red linear correlation between the pore size by PALS and the refractive index gives a refractive index of nonporous $\mathrm{SiO}_{2}$ of 1.483, comparable to that from EP. The results indicate that the open porosities/interconnectivities and pore sizes measured by PALS are in good agreement with those by EP.

\section{Conclusions}

PAES and PALS based on slow positron beams as well as EP combined with heptane adsorption were applied to investigate the open mesoporosity/interconnectivity and mesopore size for the mesoporous silica films templated by different triblock copolymers. Both the o-Ps $3 \gamma$ annihilation fractions and heptane adsorption-desorption isotherms show 
more closed pores in the film with P103 and well connected mesopores in the respective films with F38, F88 and F127. The linear relationship between the pore sizes with the slope of 1 estimated by PALS and EP displays a good consistency with each other. For the film fabricated by P103, the PSD peak deduced by the longest-lived o-Ps lifetimes is more remarkable than $\mathrm{BJH}$ peak by EP, which signifies higher sensitivity for PALS in determining closed pores than EP. The EP combined with heptane adsorption is a useful method for calibrating the mesopore size in highly interconnected films, while PALS is a novel, complementary probe for both closed and open pores.

Supplementary Materials: The following are available online at https:/ / www.mdpi.com/article/10 $.3390 /$ ma14123371/s1, Figure S1: The schematic diagram of the apparatus of heptane adsorption.

Author Contributions: Conceptualization, C.H.; methodology, C.H.; validation, B.X. and J.L. (Jingjing Li); formal analysis, B.X. and J.L. (Jingjing Li); investigation, B.X., J.L. (Jingjing Li) and J.L. (Jiale Lai); resources, C.H.; data curation, C.H. and B.X.; writing-original draft preparation, B.X.; writingreview and editing, C.H.; visualization, B.X., J.L. (Jiale Lai), X.L. and T.H.; supervision, C.H.; project administration, C.H.; funding acquisition, C.H. and B.X. All authors have read and agreed to the published version of the manuscript.

Funding: This research was funded by the National Key R\&D Program of China (2019YFA0210003), the National Natural Science Foundation of China (11705029), the Guangdong Basic and Applied Basic Research Foundation (2020A1515110817), the Innovation Team of Universities of Guangdong Province (2020KCXTD011), the Engineering Research Center of Universities of Guangdong Province (2019GCZX002), the Guangdong Key Laboratory for Hydrogen Energy Technologies (2018B030322005).

Institutional Review Board Statement: Not applicable.

Informed Consent Statement: Not applicable.

Data Availability Statement: Data contained within the article regarding the $I_{3 \gamma}-E_{\text {in }}$ curves and the heptane adsorption-desorption isotherms of the films with F38 and F127 were published previously by American Physical Society and are available at https:/ / doi.org/10.1103/PhysRevB.86.075415 (accessed on 17 May 2021) with the permission of Copyright 2012 American Physical Society. The positron annihilation lifetime spectra of the films with P103, F38 and F127 were reported previously in Elsevier and are available at https: / / doi.org/10.1016/j.radphyschem.2006.03.036 (accessed on 17 May 2021) with the permission of Copyright 2006 Elsevier.

Conflicts of Interest: The authors declare no conflict of interest.

\section{References}

1. Tanaka, S.; Nishiyama, N.; Oku, Y.; Egashira, Y.; Ueyama, K. Nano-Architectural Silica Thin Films with Two-Dimensionally Connected Cagelike Pores Synthesized from Vapor Phase. J. Am. Chem. Soc. 2004, 126, 4854-4858. [CrossRef] [PubMed]

2. He, C.Q.; Xiong, B.Y.; Mao, W.F.; Kobayashi, Y.; Oka, T.; Oshima, N.; Suzuki, R. On determining the entrance size of cage-like pores in mesoporous silica films by positron annihilation lifetime spectroscopy. Chem. Phys. Lett. 2013, 590, 97-100. [CrossRef]

3. He, C.Q.; Muramatsu, M.; Ohdaira, T.; Kinomura, A.; Suzuki, R.; Ito, K.; Kabayashi, Y. Positron annihilation studies of mesoporous silica films using a slow positron beam. Appl. Surf. Sci. 2006, 252, 3221-3227. [CrossRef]

4. Yu, C.Z.; Fan, J.; Tian, B.Z.; Stucky, G.D.; Zhao, D.Y. Synthesis of Mesoporous Silica from Commercial Poly(ethylene oxide)/Poly(butylene oxide) Copolymers: Toward the Rational Design of Ordered Mesoporous Materials. J. Phys. Chem. B 2003, 107, 13368-13375. [CrossRef]

5. He, C.Q.; Wang, S.J. Role of pore morphology in positronium diffusion in mesoporous silica thin films and in positronium emission from the surfaces. Phys. Rev. B 2012, 86, 075415. [CrossRef]

6. $\quad$ Petkov, M.P.; Weber, M.H.; Lynn, K.G.; Rodbell, K.P. Porosity characterization by beam-based three-photon positron annihilation spectroscopy. Appl. Phys. Lett. 2001, 79, 3884-3886. [CrossRef]

7. He, C.Q.; Oka, T.; Kobayashi, Y.; Oshima, N.; Ohdaira, T.; Kinomura, A.; Suzuki, R. Evolution of pores in mesoporous silica films: Porogen loading effect. Appl. Surf. Sci. 2008, 255, 183-186. [CrossRef]

8. Petkov, M.P.; Wang, C.L.; Weber, M.H.; Lynn, K.G.; Rodbell, K.P. Positron Annihilation Techniques Suited for Porosity Characterization of Thin Films. J. Phys. Chem. B 2003, 107, 2725-2734. [CrossRef]

9. He, C.Q.; Oka, T.; Kobayashi, Y.; Oshima, N.; Ohdaira, T.; Kinomura, A.; Suzuki, R. Positronium annihilation and pore surface chemistry in mesoporous silica films. Appl. Phys. Lett. 2007, 91, 024102. [CrossRef] 
10. Gidley, D.W.; Frieze, W.E.; Dull, T.L.; Sun, J.; Yee, A.F.; Nguyen, C.V.; Yoon, D.Y. Determination of pore-size distribution in low-dielectric thin films. Appl. Phys. Lett. 2000, 76, 1282-1284. [CrossRef]

11. Yoshimoto, S.; Kumagai, K.; Hosomi, H.; Takeda, M.; Tsuru, T.; Ito, K. Effect of heat treatment on the nanoporosity of silica PECVD films elucidated by low-energy positron annihilation and ellipsometric porosimetry. J. Appl. Phys. 2017, 122, 185304. [CrossRef]

12. He, C.Q.; Muramatsu, M.; Ohdaira, T.; Oshima, N.; Kinomura, A.; Suzuki, R.; Kobayashi, Y. Tunable pores in mesoporous silica films studied using a pulsed slow positron beam. Radiat. Phys. Chem. 2007, 76, 204-208. [CrossRef]

13. Lu, Y.F.; Ganguli, R.; Drewien, C.A.; Anderson, M.T.; Brinker, C.J.; Gong, W.L.; Guo, Y.X.; Soyez, H.; Dunn, B.; Huang, M.H.; et al. Continuous formation of supported cubic and hexagonalmesoporous films by sol-gel dip-coating. Nature 1997, 389, 364-368. [CrossRef]

14. Cho, W.; Kim, T.; Char, K.; Soles, C.L. A facile method for the preferential alignment of mesochannels in silica films by solution flow. Microporous Mesoporous Mater. 2010, 131, 136-140. [CrossRef]

15. He, C.Q.; Muramatsu, M.; Oshima, N.; Ohdaira, T.; Kinomura, A.; Suzuki, R. Ageing-induced enhancement of open porosity of mesoporous silica films studied by positron annihilation spectroscopy. Phys. Lett. A 2006, 355, 73-76. [CrossRef]

16. Kobayashi, Y.; Zheng, W.; Chang, T.B.; Hirata, K.; Suzuki, R.; Ohdaira, T.; Ito, K. Nanoporous structure of sputter-deposited silicon oxide films characterized by positronium annihilation spectroscopy. J. Appl. Phys. 2002, 91, 1704-1706. [CrossRef]

17. Yu, R.S.; Ito, K.; Hirata, K.; Zheng, W.; Kobayashi, Y. Effects of coexistent pores and paramagnetic defects on positron annihilation in silicon oxide thin films. J. Appl. Phys. 2003, 93, 3340-3344. [CrossRef]

18. He, C.Q.; Suzuki, R.; Ohdaira, T.; Oshima, N.; Kinomura, A.; Muramatsu, M.; Kobayashi, Y. Study of mesoporous silica films by positron annihilation based on a slow positron beam: Effects of preparation conditions on pore size and open porosity. Chem. Phys. 2007, 331, 213-218. [CrossRef]

19. Liszkay, L.; Guillemot, F.; Corbel, C.; Boilot, J.-P.; Gacoin, T.; Barthel, E.; Pérez, P.; Barthe, M.-F.; Desgardin, P.; Crivelli, P.; et al. Positron annihilation in latex templated macroporous silica films: Pore size and ortho-positronium escape. New J. Phys. 2012, 14, 065009. [CrossRef]

20. Ito, K.; Oka, T.; Kobayashi, Y.; Suzuki, R.; Ohdaira, T. Variable-energy Positron Study of Nanopore Structure in HydrocarbonSiliconoxide Hybrid PECVD Films. Phys. Procedia 2012, 35, 140-144. [CrossRef]

21. Provencher, S.W. CONTIN: A general purpose constrained regularization program for inverting noisy linear algebraic and integral equations. Comput. Phys. Commun. 1982, 27, 229-242. [CrossRef]

22. Gidley, D.W.; Frieze, W.E.; Dull, T.L.; Yee, A.F.; Ryan, E.T.; Ho, H.-M. Positronium annihilation in mesoporous thin films. Phys. Rev. B 1999, 60, R5157. [CrossRef]

23. Dull, T.L.; Frieze, W.E.; Gidley, D.W.; Sun, J.N.; Yee, A.F. Determination of Pore Size in Mesoporous Thin Films from the Annihilation Lifetime of Positronium. J. Phys. Chem. B 2001, 105, 4657-4662. [CrossRef]

24. Oka, T.; Ito, K.; Muramatsu, M.; Ohdaira, T.; Suzuki, R.; Kobayashi, Y. Porogen Approach for the Fabrication of PlasmaPolymerized Nanoporous Polysiloxane Films. J. Phys. Chem. B 2006, 110, 20172-20176. [CrossRef]

25. Yoshimoto, S.; Ito, K.; Hosomi, H.; Takai, Y. Comparison study of mesoporous thin films characterized by low-energy positron lifetime spectroscopy and flow-type ellipsometric porosimetry. JJAP Conf. Proc. 2014, 2, 011205. [CrossRef]

26. Ito, K.; Kobayashi, Y.; Suzuki, R.; Ohdaira, T.; Yu, R.; Sato, K.; Hirata, K.; Togashi, H.; Egami, M.; Arao, H.; et al. Characterization of Porous Silicate Low-k Films by Ellipsometric Porosimetry and Variable-energy Positron Annihilation Spectroscopy. Mat. Res. Soc. Symp. Proc. 2004, 788, L8.19. [CrossRef]

27. Fatemi, S.; Moosavian, M.A.; Abolhamd, G.; Mortazavi, Y.; Hudgins, R.R. Reaction Rate Hysteresis in the Hydrotreating of Thiophene in Wide- and Narrow-Pore Catalysts during Temperature Cycling. Can. J. Chem. Eng. 2002, 80, 231-238. [CrossRef]

28. Baklanov, M.R.; Mogilnikov, K.P. Characterisation of Low-K Dielectric Films by Ellipsometric Porosimetry. Mat. Res. Soc. Symp. Proc. 2000, 612, D4.2. [CrossRef]

29. Revol, P.; Perret, D.; Bertin, F.; Fusalba, F.; Rouessac, V.; Chabli, A.; Passemard, G.; Ayral, A. Porosimetry Measurements on Low Dielectric Constant-Thin Layers by Coupling Spectroscopic Ellipsometry and Solvent Adsorption-Desorption. J. Porous Mater. 2005, 12, 113-121. [CrossRef]

30. Xiong, B.Y.; Mao, W.F.; Tang, X.Q.; He, C.Q. Positron annihilation characteristics in mesostructural silica films with various porosities. J. Appl. Phys. 2014, 115, 094303. [CrossRef]

31. Tang, X.Q.; Xiong, B.Y.; Li, Q.C.; Mao, W.F.; Xiao, W.; Fang, P.F.; He, C.Q. Development of pore interconnectivity/morphology in porous silica films investigated by cyclic voltammetry and slow positron annihilation spectroscopy. Electrochim. Acta 2015, 168, 365-369. [CrossRef]

32. He, C.Q.; Ohdaira, T.; Oshima, N.; Muramatsu, M.; Kinomura, A.; Suzuki, R.; Oka, T.; Kobayashi, Y. Evidence for pore surface dependent positronium thermalization in mesoporous silica/hybrid silica films. Phys. Rev. B 2007, 75, 195404. [CrossRef]

33. Groen, J.C.; Peffer, L.A.A.; Pérez-Ramírez, J. Pore size determination in modified micro- and mesoporous materials. Pitfalls and limitations in gas adsorption data analysis. Microporous Mesoporous Mater. 2003, 60, 1-17. [CrossRef]

34. Lancelle-Beltran, E.; Prené, P.; Boscher, C.; Belleville, P.; Buvat, P.; Lambert, S.; Guillet, F.; Boissière, C.; Grosso, D.; Sanchez, C. Nanostructured Hybrid Solar Cells Based on Self-Assembled Mesoporous Titania Thin Films. Chem. Mater. 2006, 18, 6152-6156. [CrossRef]

35. Wang, X.Q.; Liu, R.; Waje, M.M.; Chen, Z.W.; Yan, Y.S.; Bozhilov, K.N.; Feng, P.Y. Sulfonated Ordered Mesoporous Carbon as a Stable and Highly Active Protonic Acid Catalyst. Chem. Mater. 2007, 19, 2395-2397. [CrossRef] 
36. Hou, K.; Tian, B.Z.; Li, F.Y.; Bian, Z.Q.; Zhao, D.Y.; Huang, C.H. Highly crystallized mesoporous $\mathrm{TiO}_{2}$ films and their applications in dye sensitized solar cells. J. Mater. Chem. 2005, 15, 2414-2420. [CrossRef]

37. Thommes, M.; Kaneko, K.; Neimark, A.V.; Olivier, J.P.; Rodriguez-Reinoso, F.; Rouquerol, J.; Sing, K.S.W. Physisorption of gases, with special reference to the evaluation of surface area and pore size distribution (IUPAC Technical Report). Pure Appl. Chem. 2015, 87, 1051-1069. [CrossRef]

38. Brunauer, S.; Deming, L.S.; Deming, W.E.; Teller, E. On a Theory of the van der Waals Adsorption of Gases. J. Am. Chem. Soc. 1940, 62, 1723-1732. [CrossRef]

39. Barrett, E.P.; Joyner, L.G.; Halenda, P.P. The Determination of Pore Volume and Area Distributions in Porous Substances. I. Computations from Nitrogen Isotherms. J. Am. Chem. Soc. 1951, 73, 373-380. [CrossRef]

40. Khasanov, T.K. Values of the Refractive Index of Bulk Quartz. Opt. Spectrosc. 2015, 118, 655-662. [CrossRef] 